\title{
Wind kinetic energy climatology and effective resolution for the ERA5 reanalysis
}

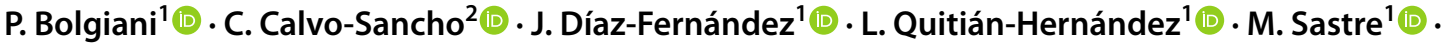

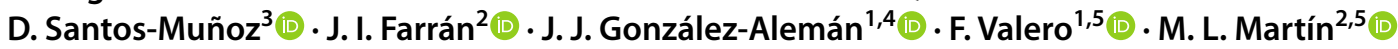

Received: 2 September 2021 / Accepted: 12 January 2022 / Published online: 29 January 2022

(c) The Author(s) 2022

\begin{abstract}
ERA5 represents the state of the art for atmospheric reanalyses and is widely used in meteorological and climatological research. In this work, this dataset is evaluated using the wind kinetic energy spectrum. Seasonal climatologies are generated for $30^{\circ}$ latitudinal bands in the Northern Hemisphere (periodic domain) and over the North Atlantic area (limited-area domain). The spectra are also assessed to determine the effective resolution of the reanalysis. The results present notable differences between the latitudinal domains, indicating that ERA5 is properly capturing the synoptic conditions. The seasonal variability is adequate too, being winter the most energetic, and summer the least energetic season. The limited area domain results introduce a larger energy density and range. Despite the good results for the synoptic scales, the reanalysis' spectra are not able to properly reproduce the dissipation rates at mesoscale. This is a source of uncertainties which needs to be taken into account when using the dataset. Finally, a cyclone tropical transition is presented as a case study. The spectrum generated shows a clear difference in energy density at every wavelength, as expected for a highly-energetic status of the atmosphere.
\end{abstract}

Keywords Energy spectrum $\cdot$ Effective resolution $\cdot$ Climatology $\cdot$ ERA5

\section{State of the art}

At the present time, most of the meteorological predictions and forecasting products are based on numerical weather prediction (NWP) models. For this reason, NWP is both a major tool and principal research field for meteorology and climatology, as well as for other earth physics sciences. As a consequence, the assessment and validation of models, their evolutions and applications constitute a permanent topic of study and discussion. One of the most important

C. Calvo-Sancho

carlos.calvo.sancho@uva.es

1 Department of Earth Physics and Astrophysics, Faculty of Physics, Universidad Complutense de Madrid, Madrid, Spain

2 Department of Applied Mathematics, Faculty of Computer Engineering, Universidad de Valladolid, Segovia, Spain

3 Danmarks Meteorologiske Institut, Copenhagen, Denmark

4 Agencia Estatal de Meteorología (AEMET), Madrid, Spain

5 Interdisciplinary Mathematics Institute, Universidad Complutense de Madrid, Madrid, Spain variables to consider in the configuration of a model for a NWP experiment is resolution. Spatial and temporal resolutions play a major role in the model's outcome (Adlerman and Droegemeier 2002; Bryan et al. 2003) but also in the computation power required to perform the task, so they need to be carefully considered before the simulation is run to be adequate to the subject of study. Moreover, thanks to the enhancement of computational resources, the constant increase of spatio-temporal resolution in NWP models has reached a challenging point for their own improvement, as nowadays limited-area mesoscalar model resolutions are verging on the microscale (Prósper et al. 2019; Siewert and Kroszczynski 2020). This represents an intrinsic problem, as it is obvious that mesoscale (400-4 km) models are not originally designed for microscale (below $4 \mathrm{~km}$ ) simulation. Thus, we face the need for new adequate parametrizations and computations for those physical processes taking place in the microscale, which had been previously disregarded (Gramelsberger 2010; Hong et al. 2004; Muñoz-Esparza et al. 2017; Sun et al. 2013). These limits of the models render necessary to know the productive limit of the resolutions used before undertaking simulation (Bolgiani et al. 2020). This effective resolution is usually considered as the 
physical distance at which the model's behaviour is reliable when considering a particular variable.

Skamarock (2004) studied a simple method of effective resolution evaluation for NWP models. The author proposes the kinetic energy dissipation curve, or kinetic energy spectrum diagram, as an indicator for effective resolution. For this diagram, the model kinetic energy dissipation is computed from the spectral decomposition of the simulated wind speed field. At a certain point, NWP models stop computing the energy in the model and proceed to filter it through diffusion so as to comply with a proper turbulent kinetic energy closure (Knievel et al. 2006; Skamarock et al. 2008). The departure of the simulated kinetic energy curve from the observed curve indicates the effective resolution, which is usually around seven times the model's grid size $(7 \Delta x)$. It has to be remarked that the computation beyond the effective resolution is not wrong in terms of physics, but a considerable uncertainty is introduced in the simulation. We can assert that the simulation below the effective resolution is not completely adequate, but that does not render it useless. For example, Skamarock (2004) defends that a finer orographic resolution or land surface processes can improve the PBL simulation, as far as the errors in energy dissipation are acknowledged. Knowing the limits and uncertainties of the tools we use is one of the motivations for the present study.

It must be noted that, the kinetic energy spectra are often derived from the wind speed. However, others atmospheric variables have also been explored. Nastrom and Gage (1985) and Cho et al. (1999) use observational data of potential temperature as well as wind components to compute the energy spectra. They conclude the horizontal wind and potential temperature have a very similar behaviour and do not depart greatly from the curve expected. Furthermore, Cho et al. (1999) compute the energy spectra with other atmospheric and air quality variables (e.g., specific humidity, $\mathrm{CO}_{2}, \mathrm{O}_{3}, \mathrm{CH}_{4}$ ). The spectra behaviour of these variables follows again the curve produced by the wind speed. According to the observations by Nastrom and Gage (1985), the kinetic energy associated with planetary and large-scale processes follows a theoretical dissipation curve proportional to $\mathrm{k}^{-3}$ (Kolmogorov 1941) while the mesoscale atmospheric energy dissipates proportionally to $\mathrm{k}^{-5 / 3}$. These upper troposphere observations show the theoretical curves falling to the microscale limit, which is considered to be at around $4 \mathrm{~km}$. In this context, Lindborg (1999, Eq. 71) uses these observations to demonstrate an equation describing the energy dissipation. Notice that the domain selected can promote differences in the observed spectrum curve due to several issues, e.g. the synoptic conditions, the geographical region of study or even the local topography (Ricard et al. 2013; Skamarock 2004). The distance of sampling will also mark the lower limit of the curve ( $2 \Delta \mathrm{x}$ as per Nyquist 1928$)$ and the longitude of the observation segment will define the upper limit of it (as it effectively filters the maximum wavelength). These conditions to the curve are also present in NWP simulations due to grid and domain sizes, and limitedarea models will introduce additional modifications to the curve (Skamarock 2004).

Several researchers have been able to adequately reproduce the observations in global and limited area NWP simulations (Abdalla et al. 2013; Koshyk and Hamilton 2001; Ricard et al. 2013; Skamarock 2004; Takahashi et al. 2006), proving the effective resolution of the respective models used. Hamilton et al. (2008) remarks that some General Circulation Models (GCM) present rather different performances at the transition from $\mathrm{k}^{-3}$ to $\mathrm{k}^{-5 / 3}$. In particular, Palmer (2001) reports that the Integrated Forecasting System [IFS; ECMWF (2016)] shows a kinetic energy spectrum that steepens rather than shallows in the mesoscale, being outperformed by other GCMs which can simulate more realistic spectra (Koshyk and Hamilton 2001; Takahashi et al. 2006). However, later results by Abdalla et al. (2013) prove that the updated versions of the IFS have corrected this issue, producing a realistic spectrum deep into mesoscale. This disagreement is a direct example of effective resolution. Palmer (2001) uses the GCM with approximately $60 \mathrm{~km}$ grid resolution, which yields an effective resolution of $\approx 420 \mathrm{~km}$, just verging out of the mesoscale, while Abdalla et al. (2013) use a version of the model at $\approx 16 \mathrm{~km}$, with an effective resolution $(\approx 109 \mathrm{~km})$ able to capture the aforementioned transition. This is in line with previous results from Takahashi et al. (2006) which already show how the resolution affects the ability to capture the spectrum. Also, this shows the limitations of GCMs for the study of fine scale phenomena and the current value of limited-area high-resolution NWP models at the present state of the art.

GCMs are not only used for operational forecasts and as boundary conditions for high-resolution NWP, but are also the basis for reanalyses, which have become a major research tool due to the proven enhancement by observations assimilation (Al-Yahyai et al. 2010; Bengtsson et al. 2017; Dee et al. 2011; Done et al. 2004; Hersbach et al. 2020; Uppala et al. 2005). Thus, knowing the energy spectra and effective resolution expected for global models and reanalyses is of paramount necessity to understand the limitations and uncertainties of these tools. Among the different atmospheric reanalyses available, the ERA5 dataset is currently considered a major reference. It represents a considerable improvement over previous versions (Hersbach et al. 2020) and is not only used as initial and boundary conditions for limited-area models but also frequently considered as an observational database (Aboobacker et al. 2021; Gil Ruiz et al. 2021; Molina et al. 2021; Olauson 2018; Rodríguez and Bech 2021; Taszarek et al. 2020; Zhang et al. 2021). In line with this, the principal objective of this paper is to provide seasonal climatological curves for the wind energy 
spectrum over the northern hemisphere and the North Atlantic area from the ERA5 data. This aims to procure basal curves for further studies where no observational data is available, and additionally to be used as a reference for highresolution simulations.

Another discussion related to the mesoscale energy spectrum treats the origin of the additional energy which brings the curve slope from $\mathrm{k}^{-3}$ up to $\mathrm{k}^{-5 / 3}$ (Hamilton et al. 2008; Takahashi et al. 2006). Some results suggest that non-linear downscale energy cascades force the mesoscalar spectrum to a higher energy state (Lindborg 2007; Lindborg and Cho 2001; Tulloch and Smith 2006; VanZandt 1982). In line with this, Arimitsu and Arimitsu (2005) conclude that the synoptic part of the curve is a result of the global structure of turbulence, which is then followed by an inertial range controlled by the dissipative structure in turbulence, both sections governing the flow of turbulence. Other works support the idea of the mesoscale being energized by an upscale nonlinear motion transfer from microscale, produced mainly by moist convective processes and latent heat (Gage and Nastrom 1986; Lilly 1983; Vallis et al. 1997). This would be in line with the classical results by Van der Hoven (1957), which present a peak of energy at microscale most probably due to the turbulence derived from short-term high wind speeds. Idealized simulations by Hamilton et al. (2008) show a partial forcing from both mechanisms affecting the mesoscalar spectra. This suggests that major convective and latent heat processes should alter the energy curves in NWP simulations. Thus, a secondary objective of this article is to compare the climatological spectra with those produced for a case study, namely, a subtropical cyclone transitioning to a tropical cyclone in the North Atlantic area, where convective processes are prevalent in the evolution of the phenomenon.

This work is organized as follows: Sect. 2 presents the data used and methodology followed for producing the results, shown and discussed in Sect. 3, along with the case study; Sect. 4 yields the conclusions of this study.

\section{Data and methodology}

The ERA5 climate reanalysis (Hersbach et al. 2020) is the most updated dataset and constitutes the fifth-generation reanalysis created by the European Centre for Medium-Range Weather Forecasts (ECMWF). This atmospheric reanalysis represents the next step with respect to the previous ERA-40 (Uppala et al. 2005) and ERA-Interim (Dee et al. 2011) databases, improving the time coverage and spatial resolution. ERA5 is freely available through the EU-funded Copernicus Climate Change Service (CDS Copernicus 2020). The set is based on the IFS (Cy41r2) and holds quality-controlled uniform data from 1979 to present, with preliminary data available from 1950 to 1978 . Also, work is in progress to provide the reanalysis in almost real-time conditions; at the date of writing of this paper, the product is available up to five days prior to the current. The resolution of the ERA5 is a big enhancement from the previous reanalysis. The horizontal grid resolution is $0.25^{\circ}$ (approximately $27.8 \mathrm{~km}$ in latitude), re-grided from the $31 \mathrm{~km}$ resolution of the model. The vertical resolution includes 37 pressure levels, from $1000 \mathrm{hPa}$ up to $1 \mathrm{hPa}$, interpolated from the 137 sigmapressure hybrid levels provided by the IFS. The temporal resolution is of hourly outputs. Observations from both satellites and surface-based instruments are assimilated into the global estimate, enhancing the quality of the product. A complete description of the ERA5 dataset characteristics can be found in Hersbach et al. (2020).

In the present study, the two components of the horizontal wind field (u, v) are used from the 1979-2020 dataset at 00:00, 06:00, 12:00 and 18:00 Universal Time Coordinated (UTC). The geographical domains selected are three latitudinal bands, covering the whole longitude of the northern hemisphere (periodic domains): from $00^{\circ}$ to $30^{\circ} \mathrm{N}$, from $30^{\circ}$ to $60^{\circ} \mathrm{N}$ and from $60^{\circ}$ to $90^{\circ} \mathrm{N}$. These are then limited in longitude to cover exclusively the North Atlantic area (nonperiodic or limited-area domains): from $080^{\circ}$ to $010^{\circ} \mathrm{W}$ for the tropical area, from $070^{\circ}$ to $000^{\circ} \mathrm{E}$ for the mid-latitudes and from $070^{\circ}$ to $020^{\circ} \mathrm{E}$ for the polar area (Fig. 1).

The kinetic energy spectra are computed following the procedure of Skamarock (2004) and Abdalla et al. (2013). The process can be outlined as follows:

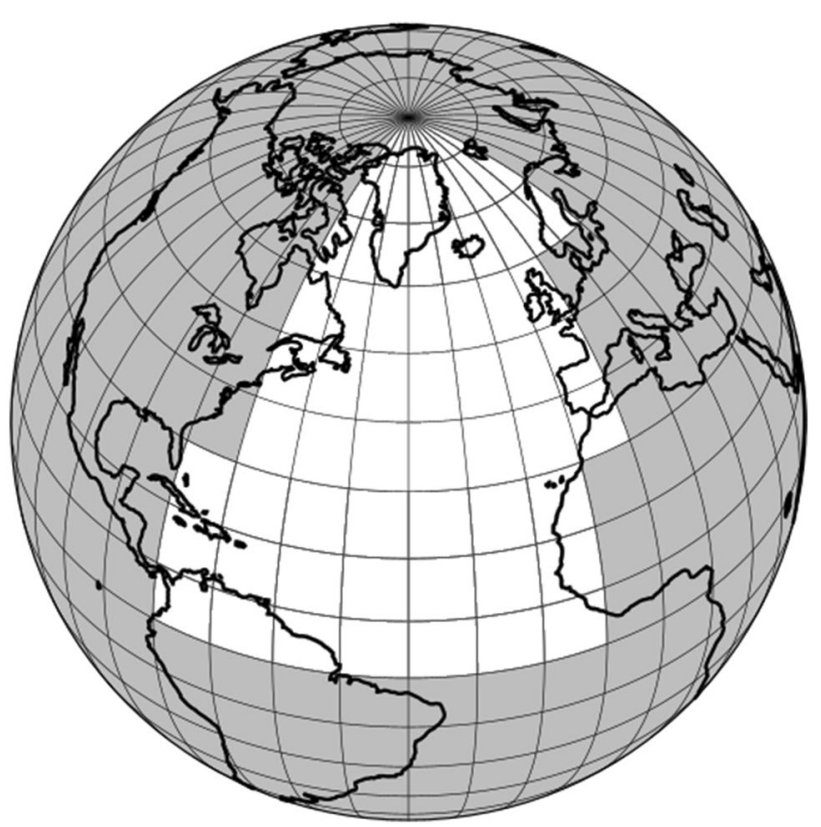

Fig. 1 Domain of study (white area) for the kinetic energy spectra over the North Atlantic Ocean. Built as the sum of three latitudinal bands 
- Wind speed field is derived using $\mathrm{u}$ and $\mathrm{v}$ components.

- Anomalies are computed by removing the average wind speed.

- In the case of limited-area domains, anomalies are also detrended, rendering the non-periodic data to periodic data for the spectral decomposition.

- Energy spectral decomposition (through Fourier Analysis) is accomplished longitudinal-wise using single vertical levels.

- The obtained energy spectra are averaged over latitude, yielding a single result for each time step.

- Plots are redimensioned into wave number and energy density for easier understanding (from frequency and variance), using the ERA5 latitudinal resolution.

- The energy spectra for each time step are then plotted together with the corresponding total average. The Lindborg (1999) energy dissipation curve is added for reference.

In preliminary results several levels and monthly curves were evaluated (not shown). The spectra for different isobaric surfaces perform as expected, in line with Skamarock (2004), showing more energy at synoptic scales for higher levels and shallower curves for lower levels. The curves for each month do not show important differences as to be presented individually. Therefore, seasonal climatologies are produced at $500 \mathrm{hPa}$, as these are considered the most representative ones for this study. Also, it is worth mentioning that, as we are evaluating the energy on single levels using a large domain, the potential energy differences can be overlooked, and the contribution of the kinetic energy can be nearly considered as the whole energy of the system. Finally, it has to be noted that the same methodology was applied to the ERA5 monthly averages for wind speed. The average curves produced by these (not shown) are very similar to those produced by the aforementioned 6-h data. Thus, it was decided to shown results of only the later dataset in attention to the high temporal resolution provided.

\subsection{Case study}

For the case study a highly active atmospheric system, a tropical storm formed by a tropical transition process (Davis and Bosart 2004), was selected due to the prominent convective activity and strong winds involved in the process. Among the multiple events available, storm Delta is to be evaluated (Beven 2005). This storm severely hit the Canary Islands archipelago in November 2005. Delta caused several casualties and many injuries, power outages, flooding and landslides. The system began to develop south-west of the Azores Islands on 19 NOV 2005 and gained subtropical cyclone characteristics on 22 NOV. By 23 NOV 2005 at 12:00 UTC the system underwent a tropical transition and continued intensifying until $27 \mathrm{NOV}$. The storm moved north-west and degraded to extratropical category with a warm-core just before hitting the Canary Islands on $28 \mathrm{NOV}$ 2005 (Sánchez-Laulhé and Martin 2006). Storm Delta was detected by GPS measurements in the isle of La Palma and in the isle of Gran Canaria, showing an increase of rainfall and intensity of wind several hours prior to the effects of Delta on the ground (Seco et al. 2009). It is interesting to note, that during a tropical transition the cold-core cyclone is progressively losing its asymmetrical nature and is acquiring characteristics typical of warm-core symmetrical tropical cyclones. These transitions are of particular interest in terms of kinetic and thermodynamic atmospheric energy, expecting notable differences against the climatology in the energy spectra generated.

The data retrieved from the ERA5 dataset has a spatial domain (Fig. 2) restricted to $\pm 11^{\circ}$ from the approximate centre of the system at the moment of transition, $27^{\circ} \mathrm{N} 041^{\circ}$ $\mathrm{W}$. The time window considered is $\pm 36 \mathrm{~h}$ also centred at the
Fig. 2 Domain of case study (white area) of tropical storm Delta

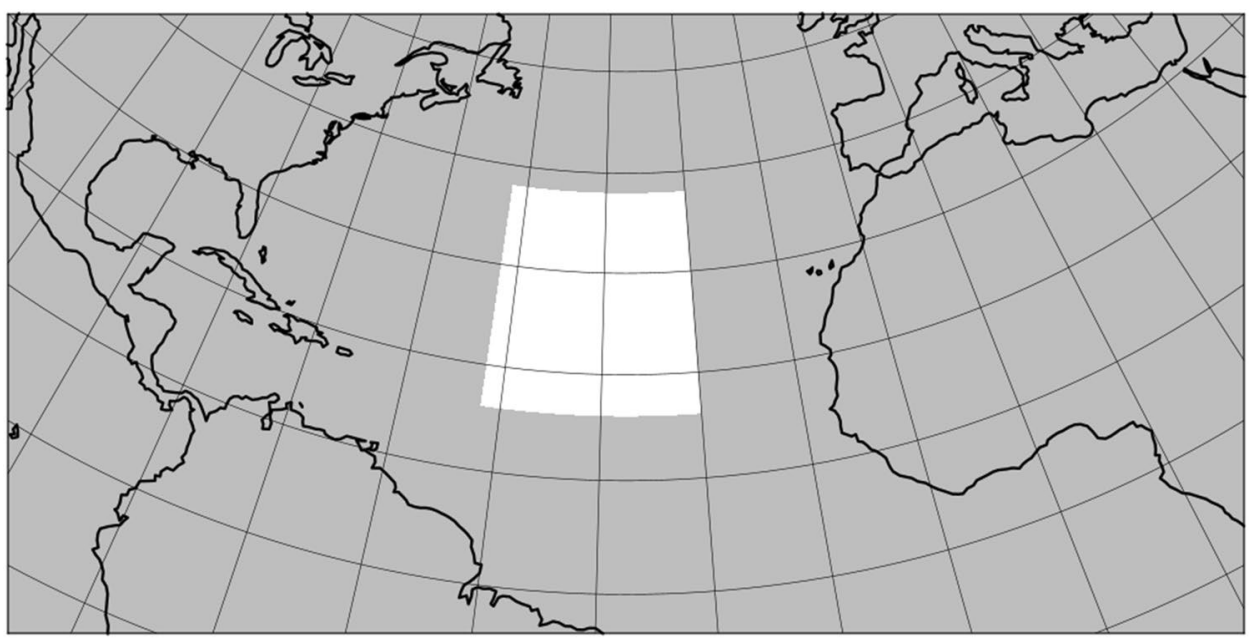


approximate moment of transition, 12:00 UTC 23NOV2005. The energy spectra are obtained using the aforementioned procedure. Also the sea level pressure, $500 \mathrm{hPa}$ geopotential height, and surface and $500 \mathrm{hPa}$ wind speed and direction fields are plotted for assessment of the situation.

\section{Results and discussion}

The results for the North Hemisphere latitudinal bands are shown in Fig. 3, while the results for the North Atlantic are presented in Fig. 4. A seasonal comparison is shown in Fig. 5 and a latitudinal comparison in Fig. 6. These figures are analysed several times in the paper, as the results for the effective resolution and the climatologies are evaluated in separate subsections. The results for the case study are then shown in Fig. 8. For the sake of simplicity, in the discussion the seasons are named: DJF for December, January and February; MAM for March, April and May; JJA for June, July and August; SON for September, October and November. Also, the latitudinal band from $00^{\circ}$ to $30^{\circ} \mathrm{N}$ is named Tropical, the band from $30^{\circ}$ to $60^{\circ} \mathrm{N}$ is named Middle and the band from $60^{\circ}$ to $90^{\circ} \mathrm{N}$ is named Polar.

Before initiating the discussion, it must be noted that the numerical differences between the average curves are computed and the Mann-Whitney U test (Mann and Whitney 1947) is used to check the statistical significance of these differences. This is a non-parametric test of null hypothesis, for populations with equal distribution, which are compared to check the independence of both groups. The p-value used is 0.01 . Every test resulted statistically significant except for the Polar MAM and SON curves for the periodic domain which are not different enough $(\mathrm{p}=0.10)$.

Also, a short discussion on the behaviour of the spectra with altitude is worth considering. As mentioned in the methodology section, the results here presented are for $500 \mathrm{hPa}$ wind speeds (Figs. 3 and 4), but preliminary results were also produced for $1000 \mathrm{hPa}$ and $250 \mathrm{hPa}$ wind speeds (not shown). When the $250 \mathrm{hPa}$ spectra are compared with the $500 \mathrm{hPa}$ results, different energy densities are only patent at synoptic scales. The upper troposphere spectra present higher densities at synoptic wavenumbers which, in turn, drive the dissipation above $10^{-5} \mathrm{rad} \mathrm{m}^{-1}$ to a steeper rate. Nevertheless, the energy in the mesoscalar range does not vary much. When the $1000 \mathrm{hPa}$ spectra are compared with the $500 \mathrm{hPa}$ results, evident differences can be seen in both spatial ranges. The near-surface spectra show lower energy densities at synoptic scales, but there are higher energy densities at the larger mesoscalar wavenumbers (around $8.10^{-5} \mathrm{rad} \mathrm{m}^{-1}$ ), generating shallower dissipation rates along the major part of the curves. The results for $250 \mathrm{hPa}$ are in accordance with those by Nastrom and Gage (1985) and Lindborg (1999), who work with observations taken between 9 and $14 \mathrm{~km}$ of altitude, and also with those by Skamarock (2004) and Hamilton et al. (2008), who also show the increment of energy densities at higher altitudes. The curves at $1000 \mathrm{hPa}$ are coincident with the conclusions derived by Van der Hoven (1957), who finds a secondary peak at microscale for near-surface wind spectra. However, it is known that upper troposphere spectra can be influenced by synoptic and planetary-scale waves, injecting energy in the system (Skamarock 2004). Also, ERA5 declares some reported issues with near-surface winds, i.e., a systematic jump in the boundary layer wind at the transition point for data assimilation, which can reflect on climatologies, and extremely large wind speeds (up to $300 \mathrm{~m} \mathrm{~s}^{-1}$ ) near orographic features (Hersbach et al. 2020). As a consequence, we proceed only with the analysis for $500 \mathrm{hPa}$ results.

\subsection{Effective resolution}

In this subsection, only the slope and shape of the curves will be assessed, disregarding the position or shape comparison with the theoretical dissipation curve.

All of the periodic domain climatological spectra (Fig. 3) seem very similar in terms of resolution. The curves present an initial shallow slope for the shortest wavenumbers, below $10^{-6} \mathrm{rad} \mathrm{m}^{-1}$, coherent with the computation of the spectra in longitude and in line with those generated by Nastrom and Gage (1985), Takahashi et al. (2006) and Hamilton et al. (2008) for zonal winds. This does not match the results by Abdalla et al. (2013) for the satellite observations and the IFS, which present a decaying curve. However, as per the aforementioned authors, the decay seems to be associated with meridional winds. It is worth noting that most of the literature only evaluates the spectra down to $10^{-6} \mathrm{rad} \mathrm{m}^{-1}$, so the curves beyond that point are mostly unknown. The climatological curves steepen when entering the synoptic scales, presenting an adequate energy dissipation close to $\mathrm{k}^{-3}$ between $10^{-6}$ and $10^{-5} \mathrm{rad} \mathrm{m}^{-1}$ wavenumbers.

When mesoscale is reached, at about $10^{-5} \mathrm{rad} \mathrm{m}^{-1}$, the curves do not show the expected shallower dissipation either. As aforementioned, this was already addressed by Palmer (2001) and Hamilton et al. (2008), reaching the conclusion that GCMs do not properly represent the energy spectrum for mesoscalar winds, however it is only a matter of grid resolution. Abdalla et al. (2013) can reproduce the change in regime due to the use of $\approx 16 \mathrm{~km}$ grid resolution (IFS version T1279). Nevertheless, ERA5 is based in a version of the IFS (T639) running at $\approx 31 \mathrm{~km}$ grid size (Hersbach et al. 2020; not to be confused with the ERA5 final delivery $0.25^{\circ}$ grid size), with an effective resolution of $\approx 260 \mathrm{~km}$, or $\approx 8 \Delta \mathrm{x}$ as per Abdalla et al. (2013). Thus, the reanalysis should in theory have the ability to reproduce the transition to $\mathrm{k}^{-5 / 3}$. However, it is not seen in the spectra. On the contrary, the energy curves slightly steepen around $4.10^{-5} \mathrm{rad} \mathrm{m}^{-1}$, induced by 

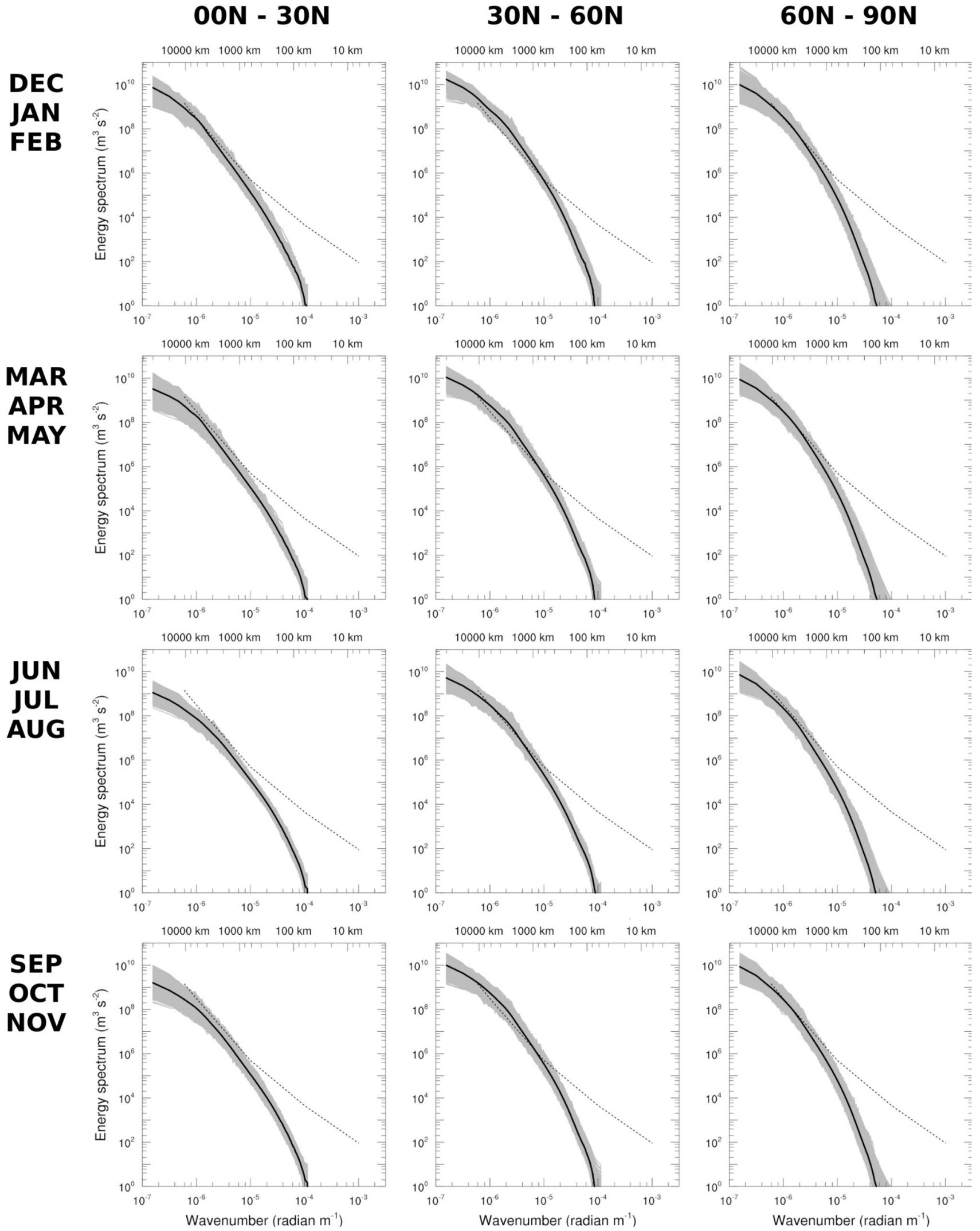

Fig. 3 Seasonal wind kinetic energy spectrum climatology for ERA5 North Hemisphere latitudinal bands. Data used in three bands: tropiGrey lines are individual spectra, black lines are averages, dashed cal $\left(00^{\circ} \mathrm{N}-30^{\circ} \mathrm{N}\right)$, Middle $\left(30^{\circ} \mathrm{N}-60^{\circ} \mathrm{N}\right)$ and Polar $\left(30^{\circ} \mathrm{N}-90^{\circ} \mathrm{N}\right)$. 

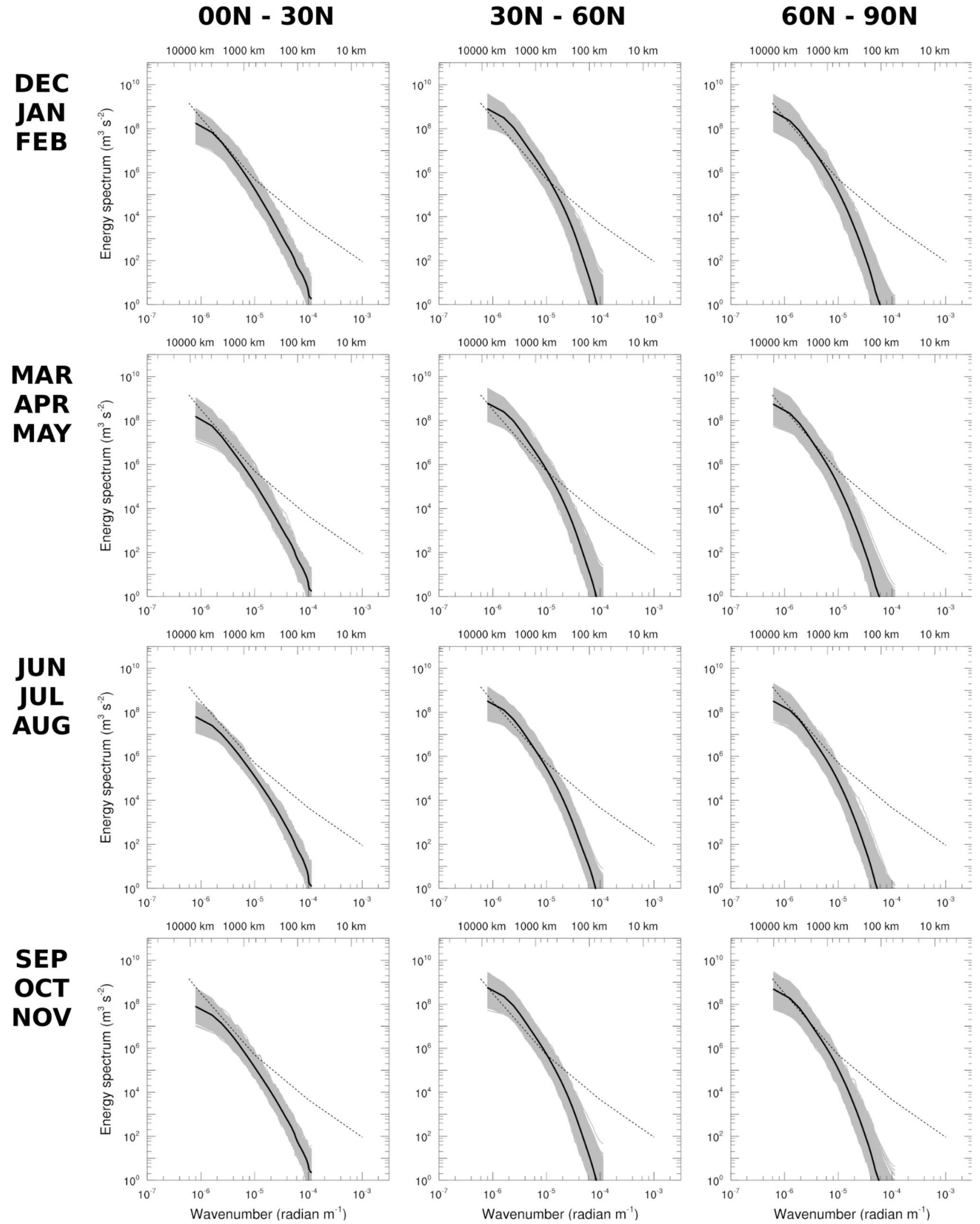

Fig. 4 Seasonal wind kinetic energy spectrum climatology for ERA5 in the North Atlantic domains described in Fig. 1. Grey lines are individual spectra, black lines are averages, dashed lines correspond to the dissipation rate as per Lindborg (1999) 

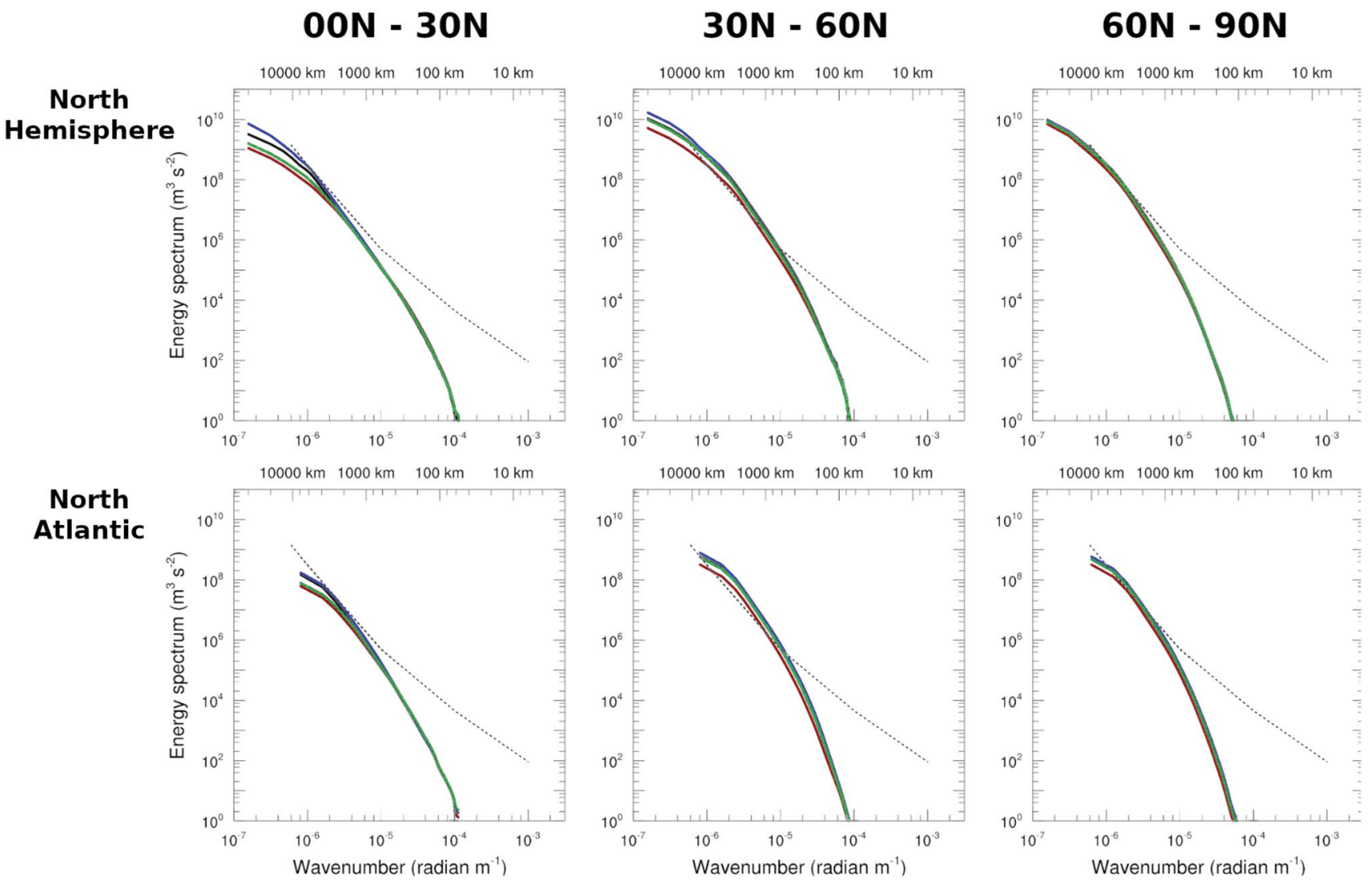

Fig. 5 Seasonal comparison of wind kinetic energy spectrum climatology for ERA5. Blue lines are DJF, black lines are MAM, red lines are JJA, green lines are SON, dashed lines correspond to the dissipation rate as per Lindborg (1999)

the damping of energy by the model and the divergence from the computed rate of dissipation. The curves end a little beyond $10^{-4} \mathrm{rad} \mathrm{m}^{-1}$, or $\approx 50 \mathrm{~km}$, as expected per $2 \Delta \mathrm{x}$.

The previous results present a remarkable aspect of the effective resolution of the ERA5. As the spectra do not present a transition to $\mathrm{k}^{-5 / 3}$, the reanalysis' effective resolution cannot be determined by the divergence to a steeper slope from the mesoscale curve. As a consequence, the limit has to be set on the point where the simulated curve diverges from the observation, as proposed by Skamarock (2004). That point is clearly seen at lower wavenumbers than expected for most spectra, approximately at $1300 \mathrm{~km}$ for the Tropical curves, at around $600 \mathrm{~km}$ for the Middle band and approximately at $1200 \mathrm{~km}$ for the Polar spectra (Fig. 5).

The results for the North Atlantic limited-area domains (Fig. 4) present spectra not reaching the $10,000 \mathrm{~km}$ wavelengths, as higher wavelengths are effectively filtered by the size of the domain. The curves are similar to those of the periodic domains in the global and synoptic scales, but present interesting differences at higher wavenumbers (Fig. 5). The divergence to steeper slopes is more pronounced for these results. The rates of dissipation are also higher, mostly for the Middle and Polar bands. Without a careful assessment, the effective resolution for the limited-area seems to be closer to the mesoscale, but that is due to the larger spread of results in these domains. When the average curve is considered, the effective resolution may be defined approximately at $1100 \mathrm{~km}$ for the Tropical spectra, around $500 \mathrm{~km}$ for the Middle curves and approximately at $1000 \mathrm{~km}$ for the Polar area.

The poor results of the ERA5 in terms of effective resolution may be an interesting topic of research, albeit beyond the scope of this paper. Clearly, the grid and resolution changes from the IFS output to the ERA5 configuration take a toll on the effective resolution. Also, the assimilation of observations and the homogenization of data may affect the final effective resolution (Neyestani et al. 2021). Regardless of the source of it, the effective resolution marks the performance limits of the reanalysis and shows the necessity of using high-resolution NWP models for any research of mesoscalar phenomena (Bauer et al. 2015; Mass et al. 2002; Neyestani et al. 2021). It also presents the energetic uncertainties fed to those models when the dataset is used as initial and boundary conditions. In fact, the effective resolution of initial and boundary conditions should be considered when selecting the domain of study for a limited-area 
Fig. 6 Latitudinal comparison of wind kinetic energy spectrum climatology for ERA5. Green lines are $00^{\circ} \mathrm{N}-30^{\circ} \mathrm{N}$, red lines are $30^{\circ} \mathrm{N}-60^{\circ} \mathrm{N}$, blue lines are $60^{\circ} \mathrm{N}-90^{\circ} \mathrm{N}$, dashed lines correspond to the dissipation rate as per Lindborg (1999)
North Hemisphere

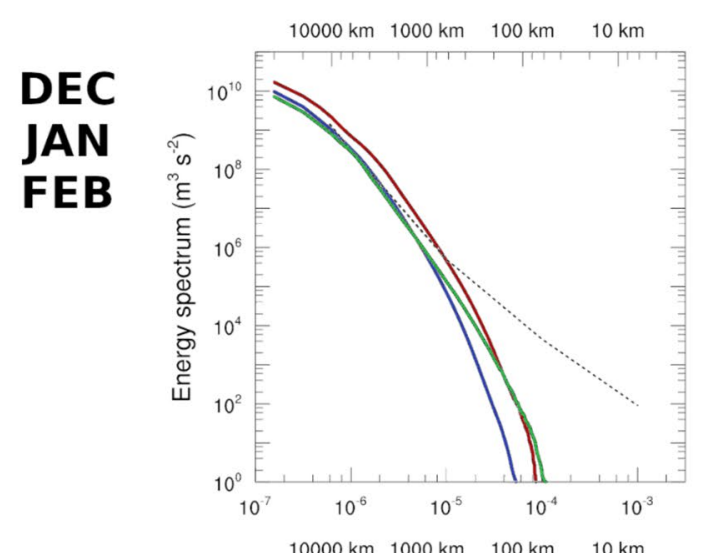
MAR
APR
MAY

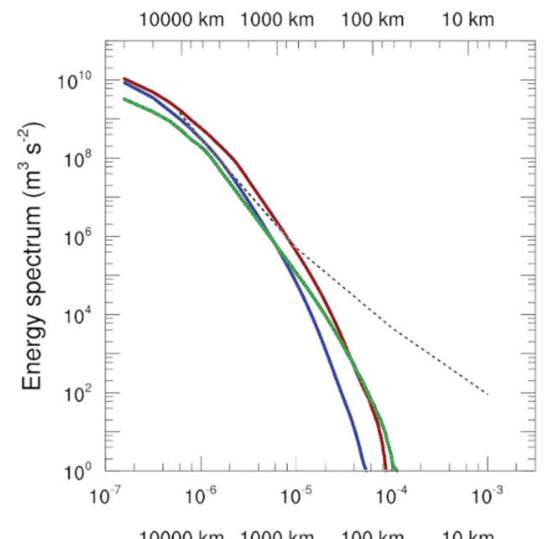

$\underset{\text { JUL }}{\text { AUU }}$

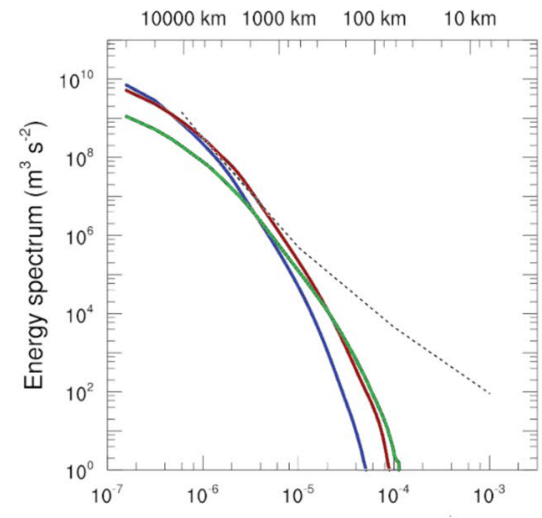

SEP
OCT
NOV

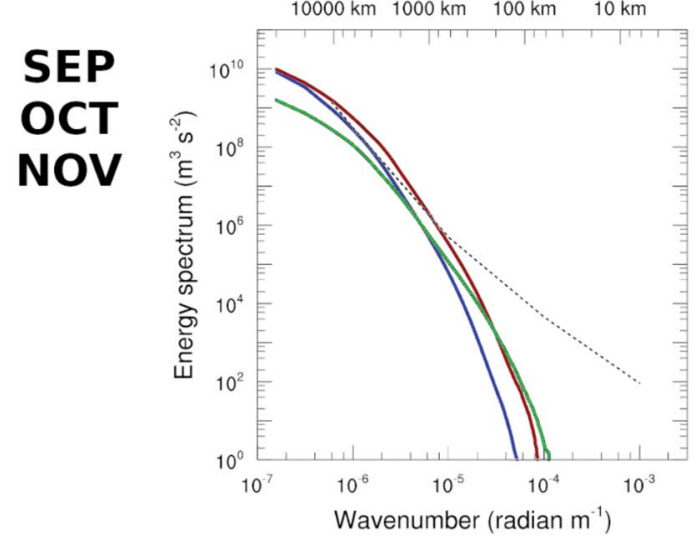

North Atlantic
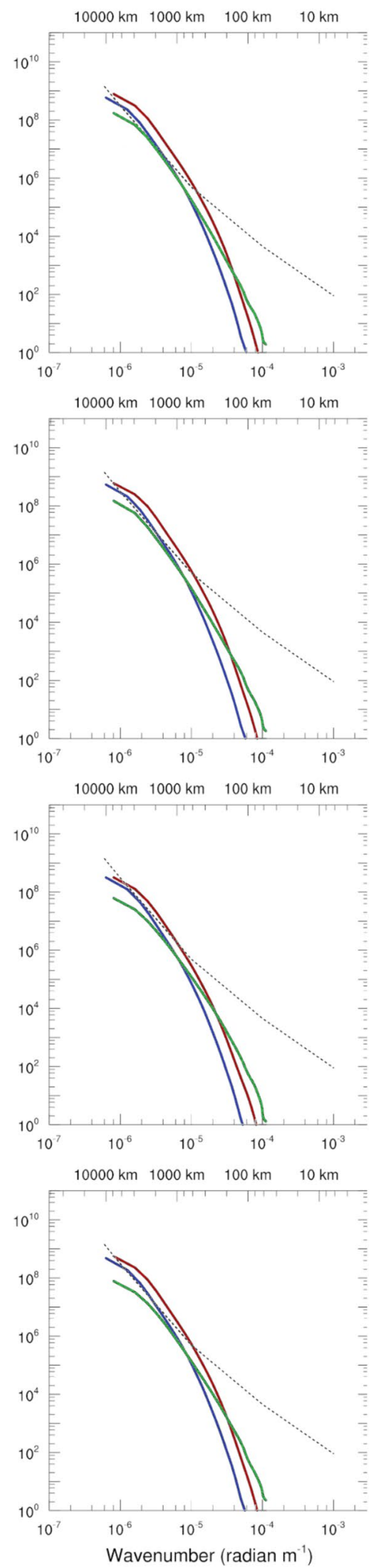
high-resolution model. If the domain has any horizontal dimension smaller than the effective resolution, it will be resolving variables from initial and boundary data which is already energetically uncertain.

\subsection{Latitudinal climatology}

The ERA5 wind kinetic energy climatology for the North Hemisphere latitudinal bands or periodic domains is presented in Fig. 3. Here, the position and comparison against the observational curve (Lindborg 1999) is assessed. It is worth noting that initially the monthly results were considered (not shown); however a seasonal pattern was evident and the differences between months are not unalike enough to justify an individual analysis.

The Polar climatology (Fig. 3) shows very little differences among the seasons, as it can also seen in Fig. 5; in fact Polar MAM and SON for the North Hemisphere are the only curves which do not result statistically independent at 0.01. A slightly smaller energy content can be found for the JJA spectrum, and a somewhat larger one for the DJF spectrum; nevertheless, the four Polar curves are almost identical across the year. The spectra perform very well in terms of energy content for the synoptic scales, in wavelengths between 1000 and $10,000 \mathrm{~km}$, being the average right on the expected curve at a wavenumber of $2 \cdot 10^{-6} \mathrm{rad} \mathrm{m}^{-1}$. Also, the four spectra present a high energy density at the lowest wavenumbers, $\approx 10^{10} \mathrm{~m}^{3} \mathrm{~s}^{-2}$, rapidly dissipating before reaching wavenumbers of $10^{-4} \mathrm{rad} \mathrm{m}^{-1}$. This shows that the Polar climatology is dominated by very energetic and stable winds at synoptic scales with almost no energy produced by the convective and diabatic phenomena in the mesoscale, as expected.

On the other hand, the Tropical climatology (Fig. 3) presents rather different spectra. Even if the curves are underestimating the energy content in the mesoscale (due to the reasons presented in Sect. 3.1), the averages consistently reach a wavenumber of $10^{-4} \mathrm{rad} \mathrm{m}^{-1}$ at the lowest energy density (Fig. 5) and present a shallower curve for the mesoscalar dissipation (Fig. 6). Thus indicating that the reanalysis properly captures the energy derived from convective processes at these latitudes. This work does not aim to shade light on the discussion about the downscale energy cascade or the upscale energy forcing from microscale phenomena, but both theories may be considered for the origin of the mentioned features of the spectra. For the synoptic scales, the Tropical climatology shows significant seasonal differences (Fig. 5). The JJA spectrum is clearly the less energetic season, presenting the lowest densities and a shallow dissipation from the global wavelengths down to $1000 \mathrm{~km}$. The results for SON show a larger energy density than the previous, but still below the observed spectrum. The curve for MAM produces a notable increase at $\approx 4000 \mathrm{~km}$, resulting in a steeper curve. Finally, the spectrum for DJF is the most energetic one for the Tropical climatology, being very similar to the Polar curve at synoptic scales (Fig. 6). Comparing these two, is evident the influence of the mesoscale phenomena in the energy density and the rate of dissipation captured by the ERA5. The origin of the climatic variability of the spectra may be linked to the Inter-Tropical Convergence Zone (ITCZ), as this forces not only the trade winds and convection, affecting the mesoscale, but also the pattern of the tropical easterly jet, influencing the energy in the synoptic range (Ba and Nicholson 1998; Jackson et al. 2009; Mohr and Thorncroft 2006). The ITCZ will invade or leave the described Tropical band along the year bringing a large variation of winds, convection and latent heat processes $(\mathrm{Ba}$ and Nicholson 1998; Futyan and Del Genio 2007).

The climatology for the Middle latitudes (Fig. 3) is the most energetic. The energy content for each season behaves similar to the Tropical band, being from less to more energetic, JJA, SON, MAM and DJF (Fig. 5). The variability of the results may be somewhat lower than for the Tropical spectra, albeit being much larger than for the Polar band. Again, the summer season shows the lower density in the synoptic scales, nevertheless, this spectrum is very close to the observational curve. The curves for the other three seasons are clearly over-energetic, most probably forced by lows with associated fronts, jet streams and modes of lowfrequency linking weather and climate anomalies over large distances across the globe (Barnston and Livezey 1987; Boer and Shepherd 1983; Martín et al. 2004; Santos-Muñoz et al. 2006; Tripoli et al. 2005; Valero et al. 2004). Regarding the mesoscale, the Middle spectra lie more or less in between the Tropical and the Polar ones, as expected (Fig. 6). Overall, the Middle latitudes produce the most adequate spectra, as the observed energy dissipation is within the range of simulated spectra for the entire synoptic scale (Kao and Wendell 1970).

\subsection{North Atlantic climatology}

The ERA5 energy spectrum climatology for the North Atlantic bands or limited-area domains is presented in Fig. 4. In terms of seasonal behaviour, the spectra show the same characteristics as the North Hemisphere latitudinal bands described in Sect. 3.2 (Fig. 5). JJA is the least energetic season while DJF presents the highest kinetic energy. The differences among the three different latitudinal bands are also in line with the previous results (Fig. 6). The North Atlantic Polar domain shows a very stable spectrum across the seasons, with little presence of energetic input from mesoscalar phenomena and a high density at synoptic wavenumbers. The Tropical domain for the North Atlantic presents a large variation during the year, with the lowest energy density for synoptic phenomena and the highest for mesoscalar. The 
Middle latitudes in the North Atlantic Ocean also generate a large seasonal variability, with the largest energy input at low wavenumbers but still showing the influence of convection and latent heat at high wavenumbers.

Despite the similarities between Figs. 3 and 4, there are two large differences between the hemispheric bands and the North Atlantic domains. The first one is the dispersion of the spectra. The limited-area domains produce a wider range for the energy density, most notable at the higher wavenumbers. This can be partially influenced by the removal of the compensating mechanisms that may happen when evaluating global scales. Selecting only the North Atlantic area can remove the effects of continents and the Pacific Ocean into the wind, thus producing results more prone to variations due to the local situation, even if the issue is about climatic frames of time.

The second difference with the periodic domain results is found in the energy levels for the North Atlantic spectra. The kinetic energy density is higher at synoptic scales for almost every season and latitudinal band (Fig. 5). The Tropical domains are the most similar ones, with overlapping curves in the mesoscalar range and almost identical curves for JJA. However, for the other three seasons a slightly higher energy content is found above wavenumbers of $10^{-5} \mathrm{rad} \mathrm{m}^{-1}$. The higher energy content is more pronounced at these wavenumbers for the Middle and Polar areas. Again, the origin of these differences may be found in the selection of the domain and the characteristics of the wind over it. On the other hand, the behaviour of the spectra for the mesoscale is different for each latitudinal band (Nastrom and Gage 1985; Stefanova and Krishnamurti 2011). The Tropical curves are almost identical below $10^{-5} \mathrm{rad} \mathrm{m}^{-1}$ for both periodic and limited-area domains. Nevertheless, while the North Atlantic Polar results show higher energy contents than the periodic domain, the curves for the Middle latitudes tend to present lower contents and increased dissipation rates.

\subsection{Case study}

The synoptic situation of the storm Delta on 22 NOV (Fig. 7a, c, e) is initially characterized by a blocking configuration with a high over the British Islands and a cutoff low near the south-west of Iberia. A deep extratropical cyclone (Delta) with a trough at high upper levels is also located south-west of the Azores Islands. The blocking pattern allows the extratropical system to isolate from the general circulation. By 23 NOV (Fig. 7b, d, f), Delta is not solely governed by quasigeostrophic processes any more and begins to be sustained by a mixture of diabatic and baroclinic processes, general characteristics of a subtropical cyclone (Evans and Guishard 2009). The synoptic situation is characterized by an upper-level cut-off low around $30^{\circ} \mathrm{N}$ $040^{\circ} \mathrm{W}$, the potential vorticity is vertically redistributed by an important latent heat release (e.g., differential diabatic heat source; not shown) and, thus, a tropical cyclone at the surface purely governed by diabatic processes.

The surface wind speed field on 22 NOV (Fig. 7c) presents the characteristical asymmetry of subtropical cyclones with a predominance of values exceeding $80 \mathrm{~km} \mathrm{~h}^{-1}$ in the north-west quadrant, sustained winds around $60 \mathrm{~km} \mathrm{~h}^{-1}$ in the centre, and lower values in the south-east quadrant of the system. This is in line with the results by Quitián-Hernández et al. $(2020,2021)$, who already noted this asymmetry in similar systems. The winds at $500 \mathrm{hPa}$ (Fig. 7e, f) show notably larger values than surface winds, clearly reinforced by a jet stream on the south-west quadrant. This is also frequent in this kind of systems, as the wind speed profile usually shows a reduction with height down to $3000 \mathrm{~m}$, and increasing cyclonic winds aloft with two jets around 600 and $400 \mathrm{hPa}$ (Evans and Guishard 2009).

The aforementioned situation indicates a state of high energy in the middle levels of the atmosphere, as expected for a subtropical storm (Evans and Guishard 2009), mainly forced by the jet stream present at $500 \mathrm{hPa}$ (Fig. 7). This is clearly reflected for the synoptic scales in the kinetic energy spectrum (Fig. 8). At wavenumbers of $10^{-5} \mathrm{rad} \mathrm{m}^{-1}$ the curve is well above by standard referenced observations (Lindborg 1999), clearly over-energized with respect to the SON Tropical climatology (Fig. 3) and the corresponding North Atlantic spectrum (Fig. 4). The excess of energy is shown into the mesoscale also, almost down to $100 \mathrm{~km}$, albeit having a larger dissipation rate too. This is in line with previous results in this work indicating that ERA5 reanalysis is capturing the convective and latent heat processes involved (Hamilton et al. 2008; Nastrom and Gage 1985; Robertson et al. 2020; Rodríguez and Bech 2021). However, this is only partially achieved, as there is no sign of the transition to $\mathrm{k}^{-5 / 3}$ and the amount of energy produced by convection in a tropical transition process is also above average. Overall, the resulting spectrum is according to the expectations and adequate to the atmospheric situation described, within the limitations of the ERA5. Nevertheless, these results are not appropriate enough to perform an in-depth study of a subtropical cyclone or any other atmospheric phenomena governed by mesoscalar processes. The uncertainties introduced by the dataset at mesoscalar ranges make it advisable to use a high-resolution NWP model for the simulation of this kind of meteorological systems.

\section{Conclusions}

The present study evaluates the climatology of wind kinetic energy for the ERA5 dataset following the energy spectrum methodology proposed by Skamarock (2004). The results have been generated using the $500 \mathrm{hPa} u$ and $\mathrm{v}$ wind 


\section{2:00 UTC November 22}
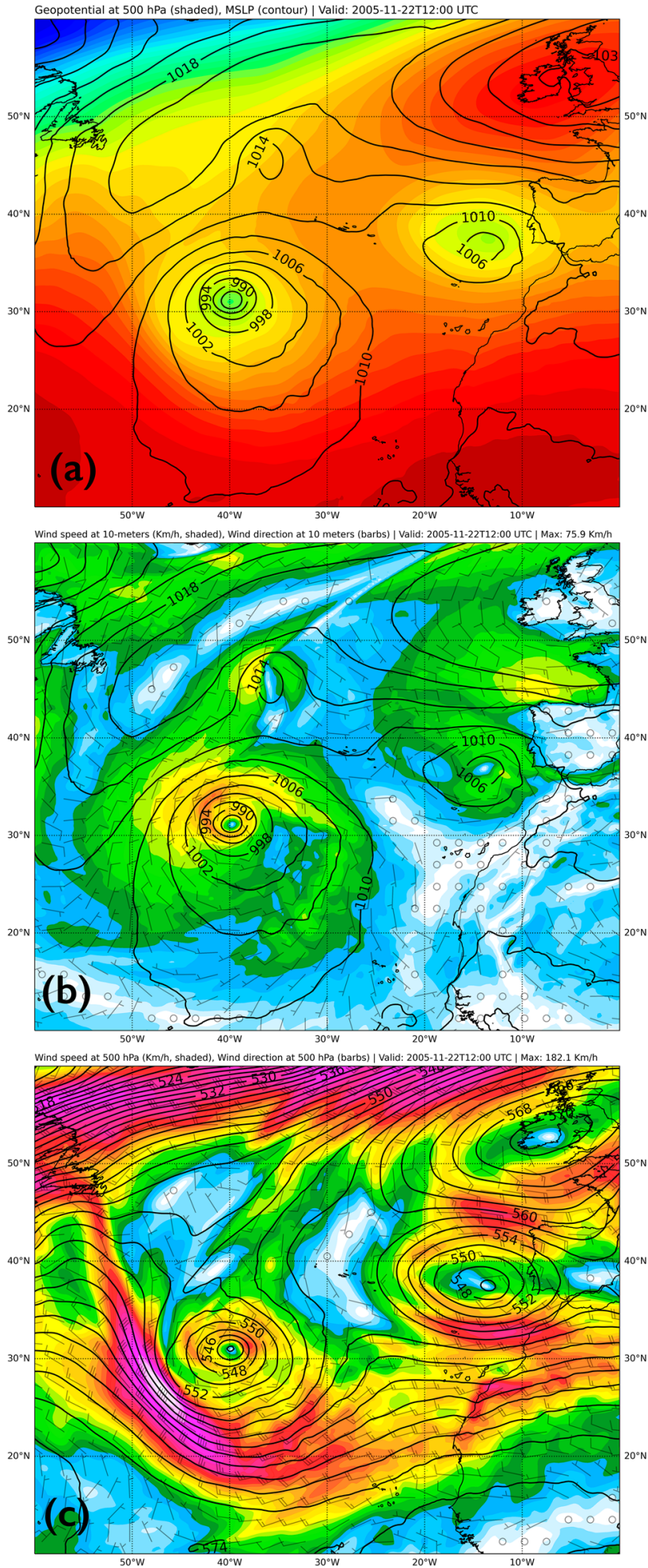

Fig. 7 a, b Mean sea level pressure (hPa, contours) and $500 \mathrm{hPa}$ geopotential height (dm, shaded). c, d 10-m wind speed $\left(\mathrm{km} \mathrm{h}^{-1}\right.$, shaded), direction (barbs) and mean sea level pressure (hPa, con-

\section{2:00 UTC November 23}
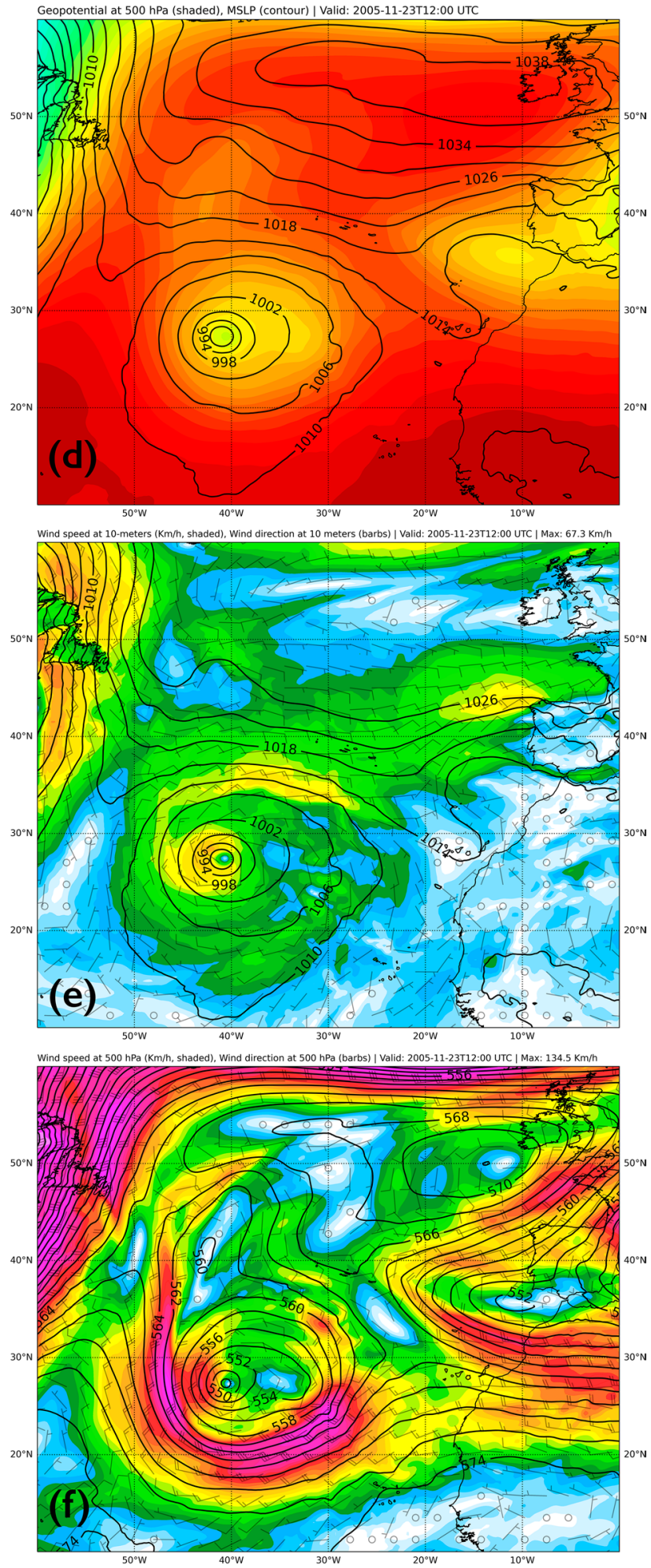

tours). e, f $500 \mathrm{hPa}$ wind speed $\left(\mathrm{km} \mathrm{h}^{-1}\right.$, shaded), direction (barbs) and $500 \mathrm{hPa}$ geopotential (gpm, contours) 


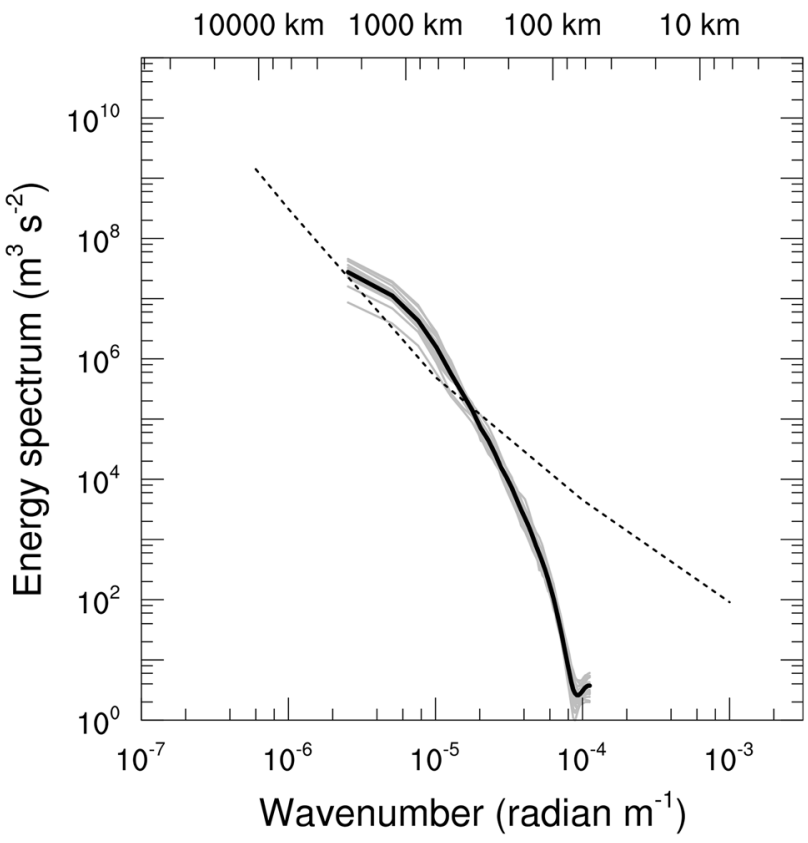

Fig. 8 ERA5 wind kinetic energy spectrum at $500 \mathrm{hPa}$ for the domain of storm Delta from 00:00 UTC 22 NOV 2015 to 00:00 UTC 25 NOV 2015. Grey lines are individual spectra, the black line is the average, the dashed line corresponds to the dissipation rate as per Lindborg (1999)

components, from 1979 to 2020, with 6-hourly data outputs and $0.25^{\circ}$ horizontal resolution. The climatologies are presented in $30^{\circ}$ latitudinal bands, for the Northern Hemisphere and the North Atlantic areas. These spectra are also used to determine the effective resolution of the reanalysis. Finally, a case study for a tropical transition is presented, to assess the adequacy of the ERA5 to evaluate this type of phenomena. The major conclusions derived from the results are hereby presented:

- The ERA5 dataset is able to properly capture the synoptic scale kinetic energy spectrum, as defined from observations (Lindborg 1999; Nastrom and Gage 1985).

- The simulated spectra are not properly reproducing the energetic densities expected at mesoscalar ranges, in contradiction with previous studies on the IFS model (Abdalla et al. 2013). They do not show the dissipation rate transition from $\mathrm{k}^{-3}$ to $\mathrm{k}^{-5 / 3}$ (Lindborg 1999) either. This is most probably due to the resolution changes and grid standardization processes involved in the reanalysis.

- The results drive the effective resolution to be defined between 1300 and $1100 \mathrm{~km}$ for the Tropical band, between 600 and $500 \mathrm{~km}$ for the Middle latitudes, and between 1200 and $1000 \mathrm{~km}$ for the Polar area, as per Skamarock (2004) methodology.

- The three latitudinal bands present characteristic differences, in the hemispherical and North Atlantic climatolo- gies, indicating that the ERA5 is properly reproducing the synoptic conditions, in line with Nastrom and Gage (1985), and partially capturing the mesoscalar status of each latitude. The Middle bands presents a higher energy at synoptic levels, due to westerly winds. The Tropical domains show higher mesoscalar energy contents. The Polar latitudes are the most stable, with upper wind energies right in the expected levels and no convective activity.

- There are also seasonal differences, being DJF the most energetic period and JJA the season with the least energy density. These differences are almost negligible for the Polar domains.

- When comparing the results for the North Atlantic to the hemispheric ones, it can be seen that the limited-area domain introduces a wider energy range for each wavenumber. Also, the energy content is higher in the North Atlantic, mainly at synoptic scales.

- The results for an atmospheric high energetic status, namely, cyclone Delta tropical transition, show an over-energized spectrum. When compared with the corresponding climatology curve, the expected excess of energy is reproduced by the ERA5 at synoptic and mesoscales. Nevertheless, the dissipation rates produced by the spectra show that the reanalysis' curve is not adequate to evaluate phenomena with a large forcing from convection and latent heat processes.

Reanalyses derived from GCMs provide an excellent opportunity to expand the knowledge about climatic spectra. To the authors' knowledge, this is the only climatology published for wind kinetic energy spectra. Also, it's the first time spectra have been computed covering the whole hemisphere, reaching wavelengths up to $40,000 \mathrm{~km}$. The value of ERA5 as a research tool is indisputable and here we provide a novel energetic climatology and spectral curves for future reference. The results may be used in the future to compare against different atmospheric configurations where energy may play a major role, as performed in the case study. This work may also help understanding better the adequacy and limitations of the reanalysis. Mainly for the type and scale of the atmospheric phenomena it should be used to research on. But also for the uncertainties it can introduce when used as initial and boundary conditions for high-resolution NWP models. The authors consider this later topic would be of interest for further studies. In addition, it would be worthwhile to deepen the study related to the performance of the dataset. The transformation from the GCM analysis to the final reanalysis seems to be deteriorating the results in terms of effective resolution, and this should be addressed.

Acknowledgements This work is supported by the Interdisciplinary Mathematics Institute of the Complutense University of Madrid and 
funded by the Spanish Ministry of Economy under the following research projects: PID2019-105306RB-I00 (IBERCANES), CGL201678702 (SAFEFLIGHT), PCIN-2016-080 and FEI-EU-17-16. This work is also supported by the ECMWF Special Projects SPESMART and SPESVALE. J. Díaz-Fernández acknowledges the grant supported by the Spanish Ministry of Economy and Competitiveness-FPI program (BES-2017). C. Calvo-Sancho acknowledges the grant supported by the Spanish Ministry of Science and Innovation-FPI program (PRE2020-092343).

Author contributions PB contributed to the manuscript design, methodology preparation, data collection and analysis. CC-S contributed to the manuscript design, methodology preparation, data collection and analysis. JD-F contributed to the manuscript design and composition of the manuscript. LQ-H contributed to the manuscript design and composition of the manuscript. MS contributed to the manuscript design, methodology preparation, data collection and analysis. DS-M contributed to the manuscript design and composition of the manuscript. JIF contributed to the manuscript design, data collection and composition of the manuscript. JJG-A contributed to the manuscript design and composition of the manuscript. FV contributed to the manuscript design and composition of the manuscript. MLM contributed to the manuscript design, methodology preparation, data collection and analysis. All authors commented on the various previous versions of the manuscript. All authors read and approved the final manuscript.

Funding Open Access funding provided thanks to the CRUE-CSIC agreement with Springer Nature. This work is supported by the Interdisciplinary Mathematics Institute of the Complutense University of Madrid and funded by the Spanish Ministry of Economy under the following research projects: PID2019-105306RB-I00 (IBERCANES), CGL2016-78702 (SAFEFLIGHT), PCIN-2016-080 and FEI-EU-17-16. This work is also supported by the ECMWF Special Projects SPESMART and SPESVALE.

Availability of data and material The data used for this work is public and freely available through the EU-funded Copernicus Climate Change Service.

Code availability The main results of this work were obtained using the NCAR Command Language software. The scripts are available upon request.

\section{Declarations}

Conflict of interest The authors declare no conflict of interest. The funding sponsors have no participation in the execution of the experiment, the decision to publish the results, nor the writing of the manuscript.

Ethical approval Not applicable.

Consent to participate Not applicable.

Consent for publication Not applicable.

Open Access This article is licensed under a Creative Commons Attribution 4.0 International License, which permits use, sharing, adaptation, distribution and reproduction in any medium or format, as long as you give appropriate credit to the original author(s) and the source, provide a link to the Creative Commons licence, and indicate if changes were made. The images or other third party material in this article are included in the article's Creative Commons licence, unless indicated otherwise in a credit line to the material. If material is not included in the article's Creative Commons licence and your intended use is not permitted by statutory regulation or exceeds the permitted use, you will need to obtain permission directly from the copyright holder. To view a copy of this licence, visit http://creativecommons.org/licenses/by/4.0/.

\section{References}

Abdalla S, Isaksen L, Janssen P, Wedi N (2013) Effective spectral resolution of ECMWF atmospheric forecast models. ECMWF Newsl 137:19-22. https://doi.org/10.21957/rue4o7ac

Aboobacker VM, Shanas PR, Al-Ansari EMAS, Sanil Kumar V, Vethamony P (2021) The maxima in northerly wind speeds and wave heights over the Arabian Sea, the Arabian/Persian Gulf and the Red Sea derived from 40 years of ERA5 data. Clim Dyn. https://doi.org/10.1007/s00382-020-05518-6

Adlerman EJ, Droegemeier KK (2002) The sensitivity of numerically simulated cyclic mesocyclogenesis to variations in model physical and computational parameters. Mon Weather Rev. https:// doi.org/10.1175/1520-0493(2002)130\%3c2671:TSONSC\% 3e2.0.CO;2

Al-Yahyai S, Charabi Y, Gastli A (2010) Review of the use of numerical weather prediction (NWP) models for wind energy assessment. Renew Sustain Energy Rev. https://doi.org/10.1016/j.rser. 2010.07.001

Arimitsu T, Arimitsu N (2005) Multifractal analysis of the fat-tail PDFs observed in fully developed turbulence. J Phys: Conf Ser 7:101-120

Ba MB, Nicholson SE (1998) Analysis of convective activity and its relationship to the rainfall over the Rift Valley lakes of East Africa during 1983-90 using the meteosat infrared channel. J Appl Meteorol. https://doi.org/10.1175/1520-0450(1998)037\% 3c1250:aocaai\%3e2.0.co;2

Barnston AG, Livezey RE (1987) Classification, seasonality and persistence of low-frequency atmospheric circulation patterns. Mon Weather Rev. https://doi.org/10.1175/1520-0493(1987)115\% 3c1083:CSAPOL\%3e2.0.CO;2

Bauer P, Thorpe A, Brunet G (2015) The quiet revolution of numerical weather prediction. Nature 525(7567):47-55. https://doi.org/10. 1038/nature 14956

Bengtsson L, Andrae U, Aspelien T, Batrak Y, Calvo J, de Rooy W, Gleeson E, Hansen-Sass B, Homleid M, Hortal M, Ivarsson K-I, Lenderink G, Niemelä S, Nielsen KP, Onvlee J, Rontu L, Samuelsson P, Muñoz DS, Subias A, Køltzow MØ (2017) The HARMONIE-AROME model configuration in the ALADINHIRLAM NWP system. Mon Weather Rev 145(5):1919-1935. https://doi.org/10.1175/MWR-D-16-0417.1

Beven J (2005) Tropical cyclone report: tropical storm delta. 22-28 November 2005, p 12

Boer GJ, Shepherd TG (1983) Large-scale two-dimensional turbulence in the atmosphere. J Atmos Sci. https://doi.org/10.1175/15200469(1983)040\%3c0164:LSTDTI\%3e2.0.CO;2

Bolgiani P, Santos-Muñoz D, Fernández-González S, Sastre M, Valero F, Martín ML (2020) Microburst detection with the WRF model: effective resolution and forecasting indices. J Geophys Res Atmos. https://doi.org/10.1029/2020JD032883

Bryan GH, Wyngaard JC, Fritsch JM (2003) Resolution requirements for the simulation of deep moist convection. Mon Weather Rev 131(10):2394-2416. https://doi.org/10.1175/1520-0493(2003) 131\%3c2394:RRFTSO\%3e2.0.CO;2

Cho JYN, Newell R, Barrick JD (1999) Horizontal wavenumber spectra of winds, temperature, and trace gases during the Pacific exploratory missions: 1. Climatology. J Geophys Res 104:5697-5716 
CDS Copernicus (2020). ERA5 hourly data on single levels from 1979 to present. https://cds.climate.copernicus.eu/cdsapp\#!/dataset/ reanalysis-era5-single-levels?tab=overview

Davis CA, Bosart LF (2004) The TT problem: forecasting the tropical transition of cyclones. Bull Am Meteorol Soc. https://doi.org/10. 1175/BAMS-85-11-1657

Dee DP, Uppala SM, Simmons AJ, Berrisford P, Poli P, Kobayashi S, Andrae U, Balmaseda MA, Balsamo G, Bauer P, Bechtold P, Beljaars ACM, van de Berg L, Bidlot J, Bormann N, Delsol C, Dragani R, Fuentes M, Geer AJ, Vitart F (2011) The ERA-Interim reanalysis: configuration and performance of the data assimilation system. Q J R Meteorol Soc 137(656):553-597. https://doi.org/ $10.1002 /$ qj. 828

Done J, Davis CA, Weisman M (2004) The next generation of NWP: Explicit forecasts of convection using the weather research and forecasting (WRF) model. Atmos Sci Lett. https://doi.org/10. $1002 /$ asl.72

ECMWF (2016) IFS documentation. https://www.ecmwf.int/en/publi cations/ifs-documentation. Accessed 1 July 2021

Evans JL, Guishard MP (2009) Atlantic subtropical storms. Part I: diagnostic criteria and composite analysis. Mon Weather Rev. https://doi.org/10.1175/2009MWR2468.1

Futyan JM, Del Genio AD (2007) Deep convetive system evolution over Africa and the tropical atlantic. J Clim. https://doi.org/10. 1175/JCLI4297.1

Gage KS, Nastrom GD (1986) Theoretical interpretation of atmospheric wavenumber spectra of wind and temperature observed by commercial aircraft during GASP. J Atmos Sci. https://doi.org/ 10.1175/1520-0469(1986)043\%3c0729:TIOAWS\%3e2.0.CO;2

Gil Ruiz SA, Barriga JEC, Martínez JA (2021) Wind power assessment in the Caribbean region of Colombia, using ten-minute wind observations and ERA5 data. Renew Energy. https://doi.org/10. 1016/j.renene.2021.03.033

Gramelsberger G (2010) Conceiving processes in atmospheric modelsgeneral equations, subscale parameterizations, and "superparameterizations.” Stud Hist Phil Sci Part B. https://doi.org/10.1016/j. shpsb.2010.07.005

Hamilton K, Takahashi YO, Ohfuchi W (2008) Mesoscale spectrum of atmospheric motions investigated in a very fine resolution global general circulation model. J Geophys Res Atmos. https://doi.org/ 10.1029/2008JD009785

Hersbach H, Bell B, Berrisford P, Hirahara S, Horányi A, MuñozSabater J, Nicolas J, Peubey C, Radu R, Schepers D, Simmons A, Soci C, Abdalla S, Abellan X, Balsamo G, Bechtold P, Biavati G, Bidlot J, Bonavita M, Thépaut JN (2020) The ERA5 global reanalysis. Q J R Meteorol Soc. https://doi.org/10.1002/qj.3803

Hong SY, Dudhia J, Chen SH (2004) A revised approach to ice microphysical processes for the bulk parameterization of clouds and precipitation. Mon Weather Rev. https://doi.org/10.1175/15200493(2004)132\%3c0103:ARATIM\%3e2.0.CO;2

Jackson B, Nicholson SE, Klotter D (2009) Mesoscale convective systems over western equatorial Africa and their relationship to large-scale circulation. Mon Weather Rev. https://doi.org/10.1175/ 2008MWR2525.1

Kao SK, Wendell LL (1970) The kinetic energy of the large-scale atmospheric motion in wavenumber-frequency space: I. Northern Hemisphere. J Atmos Sci. https://doi.org/10.1175/15200469(1970)0272.0.CO;2

Knievel J, Bryan G, Dudhia J, Gill D, Hacker J, Klemp J, Skamarock B, Wang W (2006). Numerical weather prediction (NWP) and the WRF model-lecture slides. ATEC Forecasters' Conference, August. https://ral.ucar.edu/projects/armyrange/references/forec astconf_06/02_wrf.pdf

Kolmogorov AN (1941) The local structure of turbulence in incompressible viscous fluid for very large Reynolds numbers. Dokl Akad Nauk SSSR. https://doi.org/10.1098/rspa.1991.0075
Koshyk JN, Hamilton K (2001) The horizontal kinetic energy spectrum and spectral budget simulated by a high-resolution troposphere-stratosphere-mesosphere GCM. J Atmos Sci 58(4):329 348. https://doi.org/10.1175/1520-0469(2001)058\%3c0329: THKESA\%3e2.0.CO;2

Lilly DK (1983) Stratified turbulence and the mesoscale variability of the atmosphere. J Atmos Sci. https://doi.org/10.1175/15200469(1983)040\%3c0749:STATMV\%3e2.0.CO;2

Lindborg E (1999) Can the atmospheric kinetic energy spectrum be explained by two-dimensional turbulence? J Fluid Mech 388:259288. https://doi.org/10.1017/S0022112099004851

Lindborg E (2007) Horizontal wavenumber spectra of vertical vorticity and horizontal divergence in the upper troposphere and lower stratosphere. J Atmos Sci 64(3):1017-1025. https://doi.org/10. 1175/JAS3864.1

Lindborg E, Cho JYN (2001) Horizontal velocity structure functions in the upper troposphere and lower stratosphere: 2. Theoretical considerations. J Geophys Res Atmos 106(D10):10233-10241. https://doi.org/10.1029/2000JD900815

Mann HB, Whitney DR (1947) On a test of whether one of two random variables is stochastically larger than the other. Ann Math Stat 18:50-60

Martín ML, Luna MY, Morata A, Valero F (2004) North Atlantic teleconnection patterns of low-frequency variability and their links with springtime precipitation in the western Mediterranean. Int J Climatol. https://doi.org/10.1002/joc.993

Mass CF, Ovens D, Westrick K, Colle BA (2002) Does increasing horizontal resolution produce more skillful forecasts? The results of two years of real-time numerical weather prediction over the Pacific Northwest. Bull Am Meteorol Soc 83(3):407-441. https:// doi.org/10.1175/1520-0477(2002)0830407:DIHRPM2.3.CO;2

Mohr KI, Thorncroft CD (2006) Intense convective systems in West Africa and their relationship to the African easterly jet. Q J R Meteorol Soc. https://doi.org/10.1256/qj.05.55

Molina MO, Gutiérrez C, Sánchez E (2021) Comparison of ERA5 surface wind speed climatologies over Europe with observations from the HadISD dataset. Int J Climatol. https://doi.org/10.1002/ joc.7103

Muñoz-Esparza D, Lundquist JK, Sauer JA, Kosović B, Linn RR (2017) Coupled mesoscale-LES modeling of a diurnal cycle during the CWEX-13 field campaign: From weather to boundarylayer eddies. J Adv Model Earth Syst. https://doi.org/10.1002/ 2017MS000960

Nastrom GD, Gage KS (1985) A climatology of atmospheric wavenumber spectra of wind and temperature observed by commercial aircraft. J Atmos Sci 42(9):950-960. https://doi.org/10.1175/ 1520-0469(1985)042\%3c0950:ACOAWS\%3e2.0.CO;2

Neyestani A, Gustafsson N, Ghader S, Mohebalhojeh AR, Körnich H (2021) Operational convective-scale data assimilation over Iran: a comparison between WRF and HARMONIE-AROME. Dyn Atmos Oceans. https://doi.org/10.1016/j.dynatmoce.2021.101242

Nyquist H (1928) Certain topics in telegraph transmission theory. Trans Am Inst Electr Eng 47(2):617-644. https://doi.org/10.1109/TAIEE.1928.5055024

Olauson J (2018) ERA5: the new champion of wind power modelling? Renew Energy. https://doi.org/10.1016/j.renene.2018.03.056

Palmer TN (2001) A nonlinear dynamical perspective on model error: a proposal for non-local stochastic-dynamic parameterization in weather and climate prediction models. Q J R Meteorol Soc 127:279-304

Prósper MA, Tinoco IS, Otero-Casal C, Miguez-Macho G (2019) Downslope windstorms in the isthmus of tehuantepec during tehuantepecer events: a numerical study with WRF high-resolution simulations. Earth Syst Dyn. https://doi.org/10.5194/ esd-10-485-2019 
Quitián-Hernández L, González-Alemán JJ, Santos-Muñoz D, Fernández-González S, Valero F, Martín ML (2020) Subtropical cyclone formation via warm seclusion development: the importance of surface fluxes. J Geophys Res Atmos. https://doi.org/10.1029/ 2019JD031526

Quitián-Hernández L, Bolgiani P, Santos-Muñoz D, Sastre M, DíazFernández J, González-Alemán JJ, Farrán JI, Lopez L, Valero F, Martín ML (2021) Analysis of the October 2014 subtropical cyclone using the WRF and the HARMONIE-AROME numerical models: assessment against observations. Atmos Res. https://doi. org/10.1016/j.atmosres.2021.105697

Ricard D, Lac C, Riette S, Legrand R, Mary A (2013) Kinetic energy spectra characteristics of two convection-permitting limitedarea models AROME and meso-NH. Q J R Meteorol Soc 139(674):1327-1341. https://doi.org/10.1002/qj.2025

Robertson FR, Roberts JB, Bosilovich MG, Bentamy A, Clayson CA, Fennig K, Schröder M, Tomita H, Compo GP, Gutenstein M, Hersbach H, Kobayashi C, Ricciardulli L, Sardeshmukh P, Slivinski LC (2020) Uncertainties in ocean latent heat flux variations over recent decades in satellite-based estimates and reduced observation reanalyses. J Clim. https://doi.org/10.1175/ JCLI-D-19-0954.1

Rodríguez O, Bech J (2021) Tornadic environments in the Iberian Peninsula and the Balearic Islands based on ERA5 reanalysis. Int J Climatol. https://doi.org/10.1002/joc.6825

Sanchez-Laulhe JM, Martin F (2006) Analysis of the extratropical transition of the tropical cyclone Delta. 5a Asamblea HispanoPortuguesa de Geodesia y Geofisica, 4 pp. ISBN: 84-8320-373-1

Santos-Muñoz D, Martín ML, Luna MY, Morata A (2006) Diagnosis and numerical simulations of a heavy rain event in the Western Mediterranean Basin. Adv Geosci. https://doi.org/10.5194/ adgeo-7-105-2006

Seco A, González PJ, Ramírez F et al (2009) GPS monitoring of the tropical storm delta along the canary islands track, November 28-29, 2005. Pure Appl Geophys 166:1519-1531

Siewert J, Kroszczynski K (2020) GIS data as a valuable source of information for increasing resolution of the WRF model for warsaw. Remote Sens. https://doi.org/10.3390/rs12111881

Skamarock WC (2004) Evaluating mesoscale NWP models using kinetic energy spectra. Mon Weather Rev 132(12):3019-3032. https://doi.org/10.1175/MWR2830.1

Skamarock WC, Klemp JB, Dudhia J, Gill DO, Barker DM, Duda MG, Huang X-Y, Wang W, Powers JG (2008) A description of the advanced research WRF version 3. In Technical Report. https:// doi.org/10.5065/D6DZ069T

Stefanova L, Krishnamurti TN (2011) Kinetic energy exchanges between the time scales of ENSO and the Pacific decadal oscillation. Meteorol Atmos Phys. https://doi.org/10.1007/ s00703-011-0162-8

Sun Z, Franklin C, Zhou X, Ma Y, Zhu H, Barras V, Roff G, Okely P, Rikus L, Hu B, Bi D, Dix M, Marsland S, Yan H, Hanna N,
Golebiewski M, Sullivan A, Rashid H, Uotila P, Puri K (2013) Improvements in atmospheric physical parameterizations for the Australian Community Climate and Earth-System Simulator (ACCESS). In CAWCR Technical Report No. 061.

Takahashi YO, Hamilton K, Ohfuchi W (2006) Explicit global simulation of the mesoscale spectrum of atmospheric motions. Geophys Res Lett. https://doi.org/10.1029/2006GL026429

Taszarek M, Kendzierski S, Pilguj N (2020) Hazardous weather affecting European airports: climatological estimates of situations with limited visibility, thunderstorm, low-level wind shear and snowfall from ERA5. Weather Clim Extr 28:100243. https://doi.org/10. 1016/j.wace.2020.100243

Tripoli GJ, Medaglia CM, Dietrich S, Mugnai A, Panegrossi G, Pinori S, Smith EA (2005) The 9-10 November 2001 Algerian flood: a numerical study. Bull Am Meteorol Soc. https://doi.org/10.1175/ BAMS-86-9-1229

Tulloch R, Smith KS (2006) A theory for the atmospheric energy spectrum: depth-limited temperature anomalies at the tropopause. Proc Natl Acad Sci USA. https://doi.org/10.1073/pnas.0605494103

Uppala SM, Kållberg PW, Simmons AJ, Andrae U, da Costa Bechtold V, Fiorino M, Gibson JK, Haseler J, Hernandez A, Kelly GA, Li X, Onogi K, Saarinen S, Sokka N, Allan RP, Andersson E, Arpe K, Balmaseda MA, Beljaars ACM, Woollen J (2005) The ERA-40 re-analysis. Q J R Meteorol Soc. https://doi.org/10.1256/qj.04.176

Valero F, Luna MY, Martín ML, Morata A, González-Rouco F (2004) Coupled modes of large-scale climatic variables and regional precipitation in the western Mediterranean in autumn. Clim Dyn. https://doi.org/10.1007/s00382-003-0382-9

Vallis GK, Shutts GJ, Gray MEB (1997) Balanced mesoscale motion and stratified turbulence forced by convection. Q J R Meteorol Soc. https://doi.org/10.1256/smsqj.54208

Van der Hoven I (1957) Power spectrum of horizontal wind speed in the frequency range from 00007 to 900 cycles per hour. J Meteorol 14(2):160-164. https://doi.org/10.1175/1520-0469(1957)014\% 3c0160:PSOHWS\%3e2.0.CO;2

VanZandt TE (1982) A universal spectrum of buoyancy waves in the atmosphere. Geophys Res Lett. https://doi.org/10.1029/GL009 i005p00575

Zhang W, Villarini G, Scoccimarro E, Napolitano F (2021) Examining the precipitation associated with medicanes in the highresolution ERA-5 reanalysis data. Int J Clim. https://doi.org/10. 1002/joc.6669

Publisher's Note Springer Nature remains neutral with regard to jurisdictional claims in published maps and institutional affiliations. 